\title{
Effects of alternating current interference on corrosion of X60 pipeline steel
}

\author{
Yan-Bao Guo $^{1}$ - Cheng Liu ${ }^{1}$ - De-Guo Wang ${ }^{1}$ Shu-Hai Liu ${ }^{1}$
}

Received: 9 April 2014/Published online: 9 April 2015

(c) The Author(s) 2015. This article is published with open access at Springerlink.com

\begin{abstract}
With rapid economic development in China, demand for energy and transportation is growing. Due to the limitations of factors such as terrain and traffic, a large number of buried oil and gas pipelines are parallel to highvoltage transmission lines and electrified railways over long distances. Alternating current (AC) corrosion of pipelines is very serious in such cases. In this work, laboratory experiments were carried out with an electrochemical method in a simulated soil solution at various AC current densities from 0 to $200 \mathrm{~A} / \mathrm{m}^{2}$ and $\mathrm{AC}$ frequencies from 10 to $200 \mathrm{~Hz}$. Experimental results indicated that with an increase in the AC current density, the corrosion potential of an X60 steel electrode shifted negatively, the anodic current density increased significantly, and the corrosion rate increased. Moreover, with an increase in the $\mathrm{AC}$ frequency, the corrosion potential of the X60 electrode shifted positively and the anodic current density decreased, which led to a decrease in the corrosion rate. Furthermore, the morphology of X60 electrodes indicated that uniform corrosion occurred at a low AC current density; while corrosion pits were found on the X60 electrode surface at a high AC current density, and deep corrosion pits seriously damaged the pipelines and might lead to leakage.
\end{abstract}

Keywords Alternating current interference $\cdot$ X60 pipeline steel · Corrosion - AC current density - AC frequency

Yan-Bao Guo

gyb@cup.edu.cn

1 College of Mechanical and Transportation Engineering, China University of Petroleum, Beijing 102249, China

Edited by Yan-Hua Sun

\section{Introduction}

It has been acknowledged that the corrosion of many metallic materials and metal constructions is accelerated in the presence of alternating current (AC) interference (Pagano and Lalvani 1994; Wakelin and Sheldon 2004; Goidanich et al. 2005; Rehim et al. 2008; Eliassen and Hesjevik 2000; Xu and Cheng 2013). In the past two decades, with the rapid development of the electric power, petroleum, and transportation industries, accelerated corrosion of buried pipelines from AC stray current interference has received more and more attention (NACE Standard 1996; Gummow 1999; Movley 2005; Muralidharan et al. 2007; Li and Yang 2011). Furthermore, with the rapid development of the Chinese economy, the demand for energy and transportation is also increasing constantly and rapidly. Then, there is the requirement to build more high-voltage $\mathrm{AC}$ transmission lines, AC electrified railways, and a large number of long-distance oil pipelines. Due to the limitation of various factors, more and more pipelines are parallel to or cross high-voltage transmission lines or electrified railways in recent years. The AC stray current caused by high-voltage transmission lines or electrified railways can induce serious corrosion in buried pipelines (Kim et al. 2004; Fu and Cheng 2010; Büchler 2012; Xu et al. 2012; Tang et al. 2013), especially when buried pipelines are parallel to high-voltage transmission lines or electrified railways over long distances. Even with the application of cathodic protection (CP), when the pipeline coating contains microscopic defects or surface damage, corrosion of pipelines could also be very serious from the influence of AC stray current (Gummow 1999; Kajiyama and Nakamura 1999; Ibrahim et al. 2007; Büchler and Schöneich 2009; Ormellese et al. 2011; Fu and Cheng 2012).

Laboratory and field tests indicate that AC stray current can accelerate corrosion of pipelines. For example, Lalvani 
and Zhang (1995) indicated that AC interference would reduce anodic and cathodic polarizations, lower the passivation of metal, and increase the corrosion rate, which is similar to the influence of a depolarization agent. Song et al. (2002) indicated that the AC voltage has no effect on the AC corrosion rate of carbon steel. On the contrary, the AC current density and AC frequency have significant impacts on the corrosion rate. Pagano and Lalvani (1994) investigated corrosion properties of mild steel in seawater. Their results indicated that the corrosion rate decreased with an increase in AC frequency. Weng and Wang (2011) studied the corrosion properties of bare steel without cathodic protection, and the results showed that the relationship between the $\mathrm{AC}$ corrosion rate and the $\mathrm{AC}$ interference intensity of carbon steel obeyed a power function in the $\mathrm{AC}$ current density from 0 to $250 \mathrm{~A} / \mathrm{m}^{2}$. Yang et al. (2013) investigated the effect of the AC current density on corrosion potential, dynamic parameters (e.g., Tafel slope and corrosion current density), and impedance spectroscopy characteristics of the X70 steel using an electrochemical method. Zhu et al. (2014) investigated the stress corrosion cracking (SCC) behavior of X80 pipeline steel under the influence of various $\mathrm{AC}$ current densities and found that an AC current density of $30 \mathrm{~A} / \mathrm{m}^{2}$ was a critical value, above which the SCC susceptibility increased. Although carbon steel corrosion caused by $\mathrm{AC}$ stray current has been studied by some scholars, the existing research results cannot effectively forecast and control the AC-induced corrosion of carbon steel.

In this study, in order to investigate the effect of $\mathrm{AC}$ current density and frequency on X60 pipeline steel, laboratory experiments are carried out using a self-designed device, which simulates AC-induced corrosion, combining a potentiodynamic polarization technique and scanning electron microscopy (SEM) observation. Firstly, the polarization curves under different AC interference are measured using the potentiodynamic scanning method. Then, the electrochemical corrosion parameters including corrosion potential, Tafel slope, and anodic/cathodic current densities are obtained from the polarization curves. Finally, the AC corrosion mechanism is revealed by the electrochemical corrosion parameters and microscopic surface characterization, in order to provide a new strategy to forecast and evaluate the $\mathrm{AC}$-induced corrosion of buried pipelines.

\section{Experimental}

\subsection{Electrode and solution}

X60 pipeline steel was used as the working electrode. Its chemical components (wt $\%$ ) are $\mathrm{C} 0.1$, Si 0.4, Mn 1.3, $\mathrm{P} 0.02, \mathrm{~S} 0.025$, and Fe balance. The size of carbon steel samples was $8 \mathrm{~mm}$ in diameter and thickness. A coated copper wire was welded on the back and the carbon steel was encapsulated in epoxy resin. The specimen preparation was controlled carefully to avoid any grooves or bubbles occurring at the epoxy-steel interface. The area of the bare working electrode was $0.5 \mathrm{~cm}^{2}$ after encapsulation. An image of a working electrode is shown in Fig. 1. Before electrochemical tests, the working electrode was prepared by the following processes: (1) The sample surface was gradually polished with \#800-1500 waterproof abrasive paper, until the sample surface was mirror-like, without any scratches. (2) The sample was cleaned with acetone and deionized water. (3) A vacuum drying oven was used to dry the sample.

The electrolyte solution was a simulated soil solution. It contained $1200 \mathrm{ppm} \quad \mathrm{SO}_{4}{ }^{2-} \quad\left(1.77 \mathrm{~g} / \mathrm{L} \quad \mathrm{Na}_{2} \mathrm{SO}_{4}\right)$ and $200 \mathrm{ppm} \mathrm{Cl}^{-}\left(0.31 \mathrm{~g} / \mathrm{L} \mathrm{CaCl}_{2}\right)$. The solution was made from analytic-grade reagents and deionized water ( $\geq 18 \mathrm{M} \Omega \mathrm{cm}$, Milipore Mili-Q), of $\mathrm{pH}$ 7. Deionized water was used for the preparation of all aqueous solutions and for the rinsing process.

\subsection{Electrochemical test}

The schematic diagram of equipment is shown in Fig. 2. The equipment consists of two basic units: the direct current (DC) test part and the AC interference part. The DC test was performed using a three-electrode electrochemical workstation (Solartron 1280C). The working electrode was X60 pipeline steel, as shown in Fig. 1. The reference electrode was a saturated calomel electrode (SCE), and a platinum electrode was used as the counter electrode. In the AC interference part, AC interference was directly loaded on the working electrode. A DDS function generator (TFG2006) was used as the AC stray current source. It can control the AC interference current density and frequency while combining with an adjustable resistance box

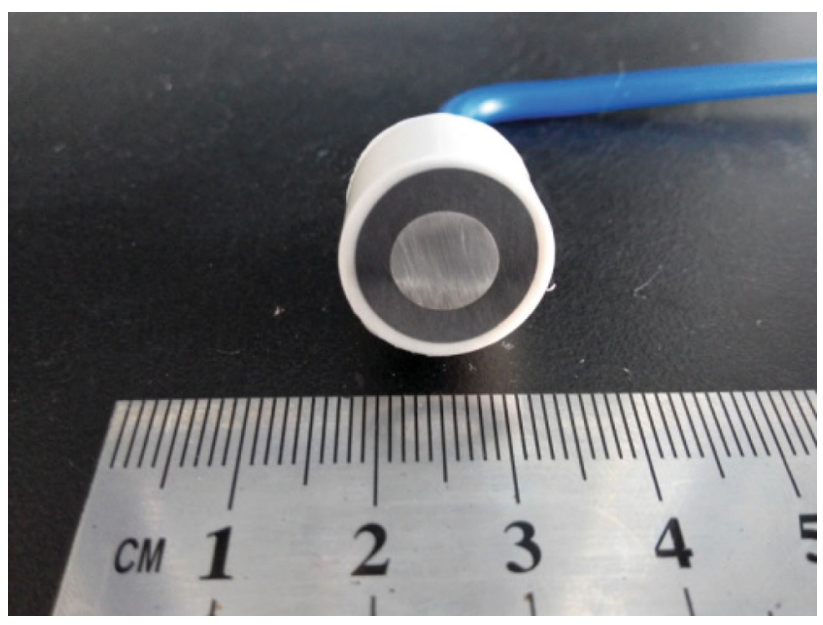

Fig. 1 X60 carbon steel working electrode 

the experimental setup for $\mathrm{AC}$ corrosion of X60 carbon steel electrode in the simulated soil solution
Fig. 2 Schematic diagram of

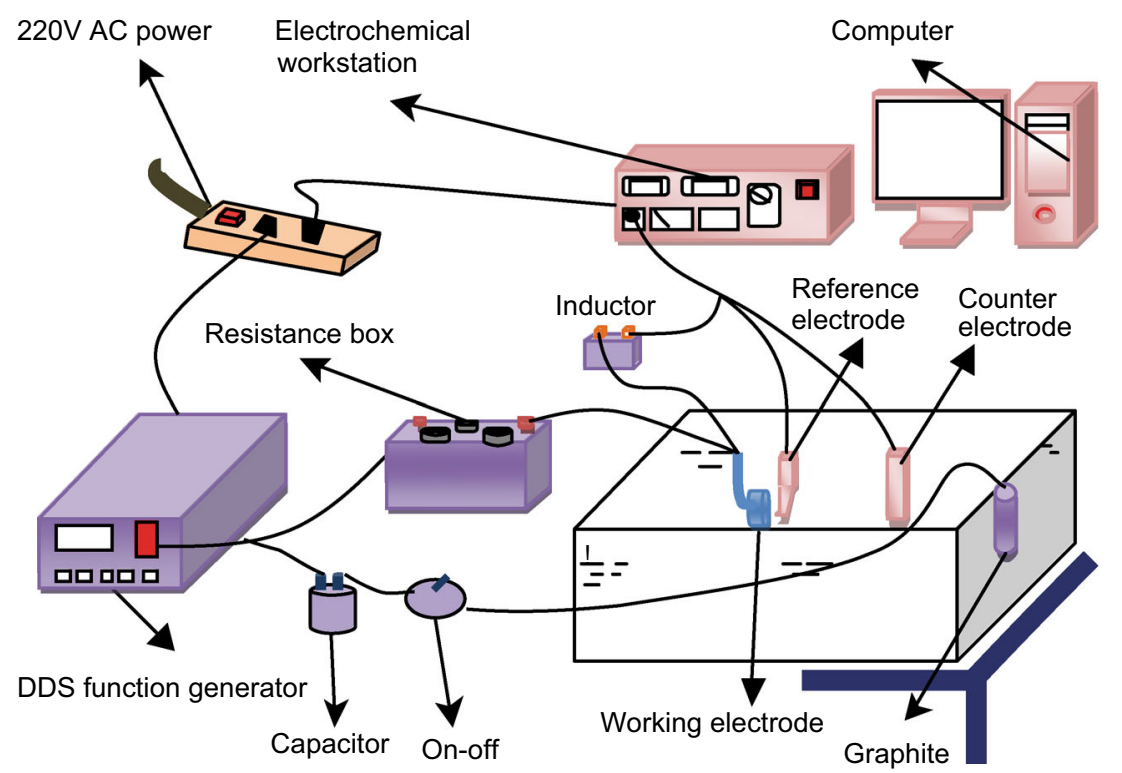

synchronously (0-9999.9 $\Omega$ ). In our testing, a capacitor $(50 \mathrm{~V}, 500 \mu \mathrm{F})$ was used in the AC interference unit to block DC signals. An inductor of $20 \mathrm{H}$ was also used in the DC test unit to eliminate the influence of AC current on the electrochemical workstation. The reference electrode was put in the Luggin capillary, and the tip of the capillary was $2 \mathrm{~mm}$ away from the carbon steel electrode surface in order to reduce the ohmic drop influence on the measurement of electric potential.

Before measurement, the carbon steel electrode was immersed in the simulated soil solution for $30 \mathrm{~min}$ until the voltage of the open circuit became stable. Then, the potentiodynamic polarization curve was recorded by the electrochemical workstation. The potential scanning rate was $0.5 \mathrm{mV} / \mathrm{s}$. The initial scanning potential was $-1300 \mathrm{mV}$ (SCE) and the final was 0 (SCE). The electrochemical parameters were obtained by fitting the polarization curves through software "CView 3.2c" which was supplied by Solartron. All the tests were operated at $22 \pm 1{ }^{\circ} \mathrm{C}$.

In order to investigate the corrosion surface, a scanning electron microscope (SEM, FEI Quanta 200F) was used to obtain images of the surface of the carbon steel electrodes before and after corrosion testing.

\section{Results and discussion}

\subsection{Effect of the AC current density on AC corrosion}

Figure 3 shows the polarization curves of X60 carbon steel measured at an $\mathrm{AC}$ frequency of $50 \mathrm{~Hz}$ and various $\mathrm{AC}$

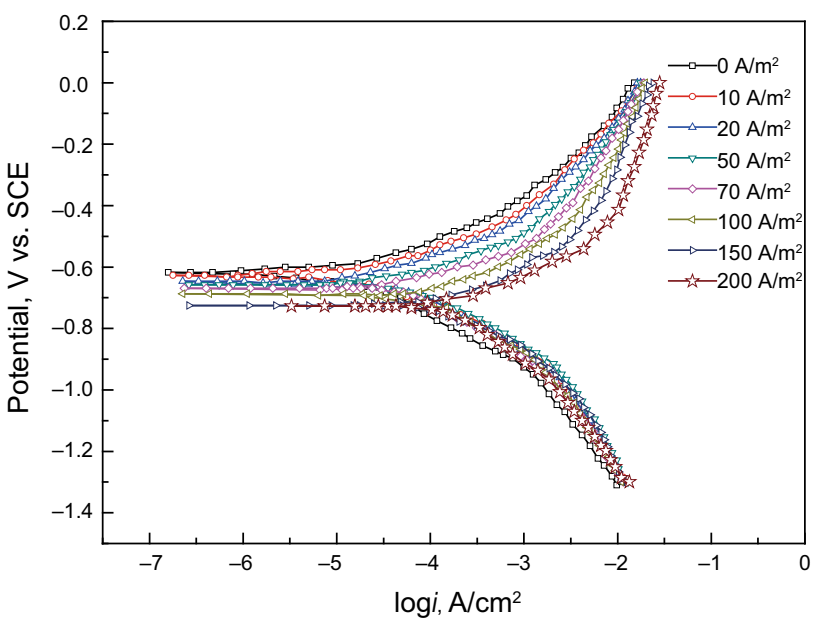

Fig. 3 Polarization curves of X60 carbon steel electrode measured at various $\mathrm{AC}$ current densities and a frequency of $50 \mathrm{~Hz}$

current densities. From Fig. 3, it can be seen that the polarization curves were different with an increase in the $\mathrm{AC}$ current density from 0 to $200 \mathrm{~A} / \mathrm{m}^{2}$. It can be also found that the AC current density had a slight effect on the cathodic reaction, but had a significant influence on the anodic reaction. With an increase in the AC interference current density, the anodic current density increased significantly and the cathodic current density also increased, but not as apparently as the anodic one. Furthermore, the increase in the AC current density caused a negative shift of the corrosion potential. The results of fitting the polarization curves from Fig. 3 are summarized in Table 1, which shows the AC current density $\left(i_{\mathrm{AC}}\right)$, corrosion potential $\left(E_{\text {corr }}\right)$, corrosion current density $\left(i_{\text {corr }}\right)$, Tafel slope $\left(\beta_{\mathrm{a}}, \beta_{\mathrm{c}}\right)$, and the ratio of $\beta_{\mathrm{a}} / \beta_{\mathrm{c}}$. 
Table 1 Electrochemical parameters of X60 carbon steel electrode at various AC current densities and a frequency of $50 \mathrm{~Hz}$

\begin{tabular}{rlllll}
\hline$i_{\mathrm{AC}}, \mathrm{A} / \mathrm{m}^{2}$ & $E_{\text {corr }}, \mathrm{V}$ versus SCE & $i_{\text {corr }}, \mathrm{A} / \mathrm{cm}^{2}$ & $\beta_{\mathrm{a}}, \mathrm{mV} / \mathrm{dec} a d e$ & $\beta_{\mathrm{c}}, \mathrm{mV} /$ decade & $\beta_{\mathrm{a}} / \beta_{\mathrm{c}}$ \\
\hline 0 & -0.618 & $1.426 \mathrm{e}-5$ & 127.15 & 168.61 & 0.75 \\
10 & -0.627 & $1.795 \mathrm{e}-5$ & 117.10 & 129.35 & 0.91 \\
20 & -0.647 & $3.758 \mathrm{e}-5$ & 141.54 & 168.82 & 0.84 \\
50 & -0.657 & $5.902 \mathrm{e}-5$ & 124.43 & 157.75 & 0.79 \\
70 & -0.676 & $6.871 \mathrm{e}-5$ & 126.85 & 207.33 & 0.61 \\
100 & -0.690 & $9.661 \mathrm{e}-5$ & 145.16 & 191.21 & 0.76 \\
150 & -0.728 & $1.390 \mathrm{e}-4$ & 163.03 & 167.52 & 0.97 \\
200 & -0.729 & $1.675 \mathrm{e}-4$ & 143.27 & 224.83 & 0.64 \\
\hline
\end{tabular}

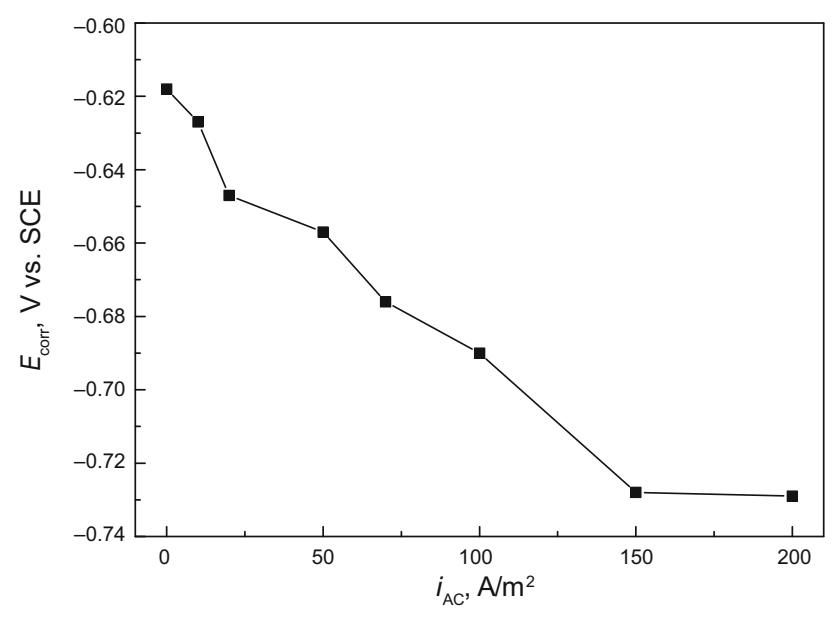

Fig. 4 Changes of corrosion potential of X60 carbon steel electrode at various $\mathrm{AC}$ current densities and a frequency of $50 \mathrm{~Hz}$

Figure 4 shows the corrosion potential of X60 carbon steel electrode at various AC current densities and a frequency of $50 \mathrm{~Hz}$. It can be seen that the corrosion potential shifted negatively with an increase in the AC current density. When the AC current acts on the carbon steel electrode, only a very small percentage of current is involved in the electrode reaction (acting as Faradaic current), while the rest of it all takes part in the chargingdischarging process (acting as non-Faradaic current) in the electric double layer between the electrode surface and the electrolyte solution. The non-Faradaic current does not participate in electrode reaction, and it almost has no effect on the corrosion of metals. It is known that when the cathodic and anodic reactions of the electrode achieve a balance without $\mathrm{AC}$ interference, the electrode potential is its corrosion potential precisely. If $\mathrm{AC}$ interference is applied on the carbon steel electrode, the faradic current which is caused by the AC interference can result in polarization of the carbon steel electrode. The polarization of the carbon steel electrode will break the balance of the electrode reaction, meanwhile the corrosion potential of the carbon steel electrode changes. However, the corrosion potential which shifts positively or negatively depends on the kinetic parameters in the process of electrode reaction (Lalvani and Lin 1994). Lalvani and Lin (1994) provided a mathematical model of the effect of AC interference on the carbon steel corrosion potential:

$E_{\text {corr }, \mathrm{AC}}=E_{\text {corr }}-\alpha$

$\alpha=\left(\frac{\beta_{\mathrm{a}}}{\frac{\beta_{\mathrm{a}}}{\beta_{\mathrm{c}}}-1}\right) \ln \left[\frac{\sum_{k=1}^{\infty} \frac{1}{(k !)^{2}}\left(\frac{E_{\mathrm{p}}}{2 \beta_{\mathrm{c}}}\right)^{2 k}+1}{\sum_{k=1}^{\infty} \frac{1}{(k !)^{2}}\left(\frac{E_{\mathrm{p}}}{2 \beta_{\mathrm{a}}}\right)^{2 k}+1}\right]$,

where $E_{\text {corr,AC }}$ is the corrosion potential with $\mathrm{AC}$ interference; $E_{\text {corr }}$ is the corrosion potential without $\mathrm{AC}$ interference; $\beta_{\mathrm{a}}$ and $\beta_{\mathrm{c}}$ are the Tafel slopes of the anodic and cathodic reactions, respectively; $E_{\mathrm{p}}$ is the peak voltage of the AC interference; and $k$ is the constant of integration.

From the mathematical model above, it can be seen that the corrosion potential with AC interference $\left(E_{\text {corr,AC }}\right)$ is a function of the Tafel slope ratio $\left(r=\beta_{\mathrm{a}} / \beta_{\mathrm{c}}\right)$ and peak voltage $\left(E_{\mathrm{p}}\right)$. In our experiments, the corrosion surface area of the X60 carbon steel electrode was constant, so the peak voltage $E_{\mathrm{p}}$ increased as the AC interference enhanced. It can be found from Table 1 that the Tafel slope ratios $\left(r=\beta_{\mathrm{a}} / \beta_{\mathrm{c}}\right)$ are all less than 1 under different $\mathrm{AC}$ interference current densities. Then, we know from a combination of Eqs. (1) with (2), when $r=\beta_{\mathrm{a}} / \beta_{\mathrm{c}}<1$, the $E_{\text {corr,AC }}$ is negatively increased with an increase in $E_{\mathrm{p}}$.

Figure 5 shows the corrosion rate of the X60 carbon steel electrode at various AC current densities and a frequency of $50 \mathrm{~Hz}$. With an increase in the AC current density, the corrosion rate of the X60 carbon steel electrode increased. Corrosion of metals is mainly determined by the anodic dissolution in the electrode reaction, that is to say, it can be characterized by the metal anodic current density. The cathodic and anodic currents were in the same magnitude and opposite direction when the corrosion reaction of the carbon steel electrode reached equilibrium. Furthermore, the electrode corrosion potential was stable. However, the AC interference would affect the electrode reaction. In the positive half-cycle of AC interference, the anodic current density increased with electrode anodic 


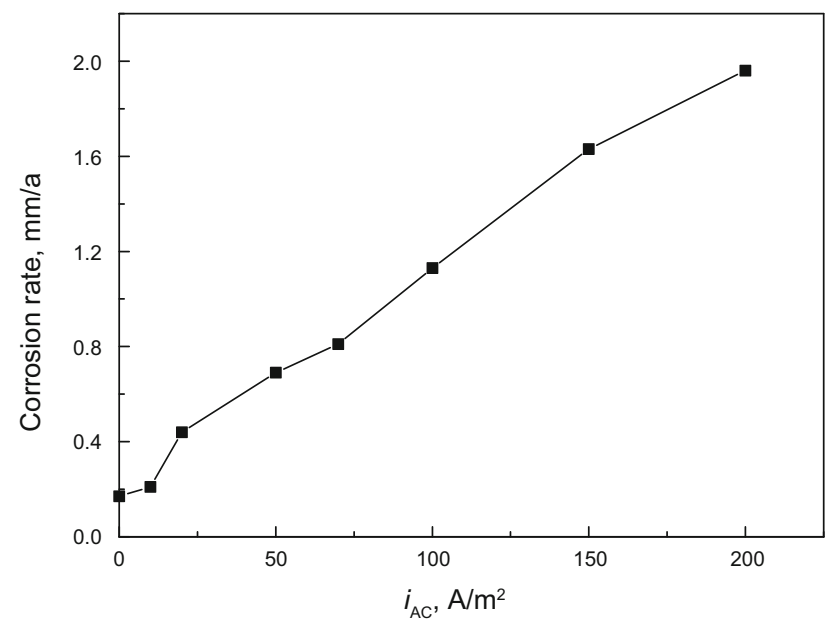

Fig. 5 Changes of corrosion rate of the X60 carbon steel electrode at various $\mathrm{AC}$ current densities and a frequency of $50 \mathrm{~Hz}$

polarization. However, in the negative half-cycle of AC interference, the anodic current density decreased with electrode cathodic polarization, but not to the same degree as the increase during the positive half-cycle because of the non-linear polarization curve of the carbon steel anodic reaction. Therefore, the complete $\mathrm{AC}$ cycle resulted in a net positive increase in the anodic current density (Goidanich et al. 2010a, b). In fact, from the view of thermodynamics, metal dissolution was the most favored process during the positive half-cycle, while oxygen reduction or hydrogen evolution was favored during the negative halfcycle (Goidanich et al. 2010a, b). It also can be seen from the polarization curves shown in Fig. 3 that the anodic current density increased significantly with an increase in the AC current density. In other words, the enhanced AC current density increased the asymmetry of changes of the anodic current density during the positive half-cycle and negative half-cycle. Thus, the corrosion of carbon steel was accelerated.

\subsection{Effect of the AC frequency on AC corrosion}

In order to investigate the effect of AC frequency on the X60 carbon steel, polarization curves of the X60 carbon steel electrode were measured at frequencies from 10 to $200 \mathrm{~Hz}$ and $\mathrm{AC}$ current densities of 50 and $150 \mathrm{~A} / \mathrm{m}^{2}$, respectively.

Figures 6 and 7 show polarization curves of the X60 carbon steel electrode measured at various frequencies and different $\mathrm{AC}$ current densities (50 and $150 \mathrm{~A} / \mathrm{m}^{2}$ ), respectively. The fitting results are presented correspondingly in Tables 2 and 3. It can be found that the anodic reaction was obviously affected by the $\mathrm{AC}$ frequency. With an increase

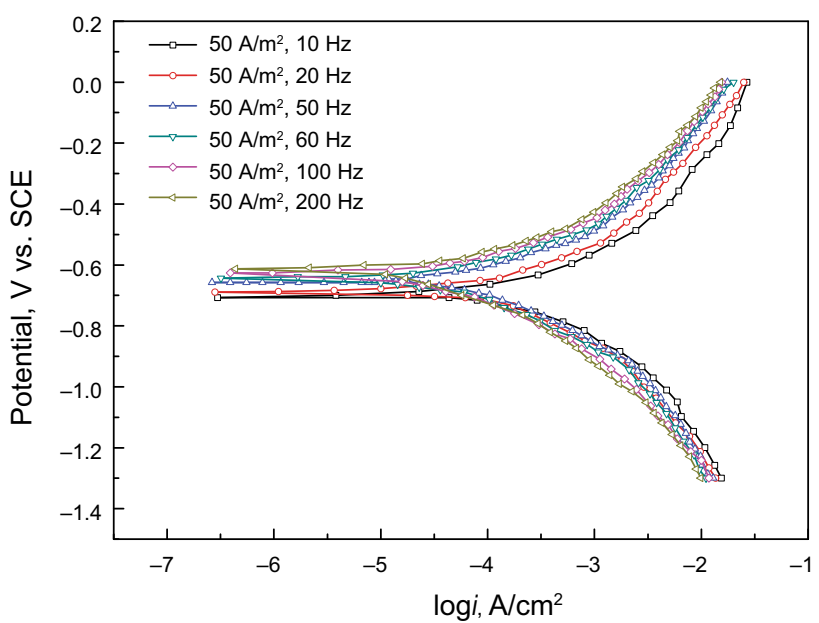

Fig. 6 Polarization curves of the X60 carbon steel electrode measured at various frequencies and an $\mathrm{AC}$ current density of $50 \mathrm{~A} / \mathrm{m}^{2}$

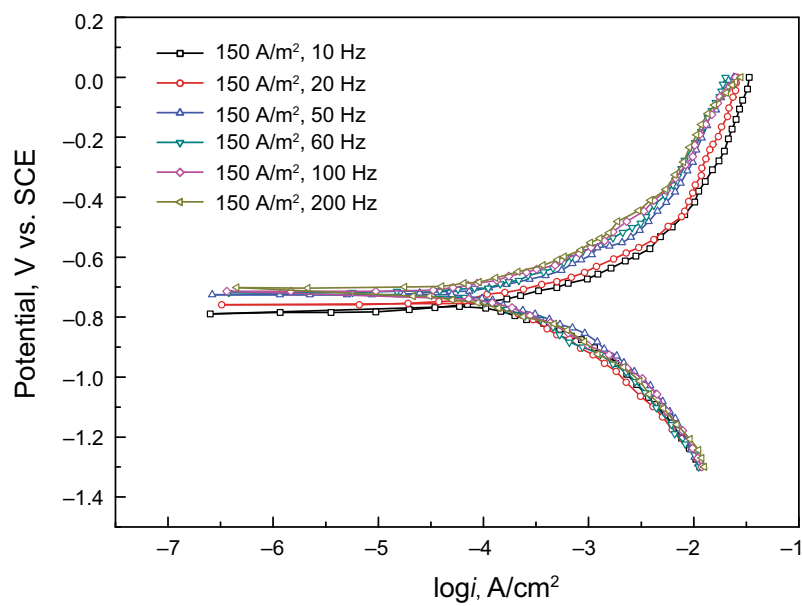

Fig. 7 Polarization curves of the X60 carbon steel electrode measured at various frequencies and an $\mathrm{AC}$ current density of $150 \mathrm{~A} / \mathrm{m}^{2}$

in the AC frequency, the anodic current density decreased. Furthermore, the corrosion potential shifted positively with the increase in the AC frequency.

The corrosion process can be expressed as an equivalent circuit which is called a Randle circuit with AC interference. There, the polarization resistance is equivalent to the electrode reaction, the electric double layer is equivalent to an interfacial capacitor, and the polarization resistance is in parallel with the interfacial capacitor. When the equivalent circuit is affected by the same AC current density of different frequencies, Yunovich and Thompson (2004) indicated that the impedance of the electric double-layer capacitor decreased with the increase in the AC frequency. This process may cause the current through the polarization resistance to decrease, which would induce a decrease in the Faradaic current. This also suggested that the current 
Table 2 Electrochemical parameters of the X60 carbon steel electrode at various frequencies and an $\mathrm{AC}$ current density of $50 \mathrm{~A} / \mathrm{m}^{2}$

\begin{tabular}{llllll}
\hline$f, \mathrm{~Hz}$ & $E_{\text {corr }}, \mathrm{V}$ versus SCE & $i_{\text {corr }}, \mathrm{A} / \mathrm{cm}^{2}$ & $\beta_{\mathrm{a}}, \mathrm{mV} / \mathrm{decade}$ & $\beta_{\mathrm{c}}, \mathrm{mV} / \mathrm{decade}$ & $\beta_{\mathrm{a}} / \beta_{\mathrm{c}}$ \\
\hline 10 & -0.704 & $1.026 \mathrm{e}-4$ & 173.91 & 141.23 & 1.23 \\
20 & -0.687 & $7.396 \mathrm{e}-5$ & 129.26 & 165.43 & 0.78 \\
50 & -0.657 & $5.902 \mathrm{e}-5$ & 124.43 & 157.75 & 0.79 \\
60 & -0.642 & $5.035 \mathrm{e}-5$ & 121.76 & 178.14 & 0.68 \\
100 & -0.627 & $3.864 \mathrm{e}-5$ & 129.63 & 185.79 & 0.70 \\
200 & -0.617 & $3.548 \mathrm{e}-5$ & 113.48 & 186.72 & 0.61 \\
\hline
\end{tabular}

Table 3 Electrochemical parameters of X60 carbon steel electrode at various current frequencies and an $\mathrm{AC}$ current density of $150 \mathrm{~A} / \mathrm{m}^{2}$

\begin{tabular}{llllll}
\hline$f, \mathrm{~Hz}$ & $E_{\text {corr }}, \mathrm{V}$ versus SCE & $i_{\text {corr }}, \mathrm{A} / \mathrm{cm}^{2}$ & $\beta_{\mathrm{a}}, \mathrm{mV} / \mathrm{decade}$ & $\beta_{\mathrm{c}}, \mathrm{mV} /$ decade & $\beta_{\mathrm{a}} / \beta_{\mathrm{c}}$ \\
\hline 10 & -0.772 & $1.972 \mathrm{e}-4$ & 166.72 & 178.80 & 0.93 \\
20 & -0.757 & $1.596 \mathrm{e}-4$ & 157.25 & 209.12 & 0.75 \\
50 & -0.728 & $1.390 \mathrm{e}-4$ & 163.03 & 167.52 & 0.97 \\
60 & -0.722 & $1.321 \mathrm{e}-4$ & 176.81 & 205.12 & 0.86 \\
100 & -0.718 & $1.170 \mathrm{e}-4$ & 164.69 & 194.18 & 0.85 \\
200 & -0.707 & $1.081 \mathrm{e}-4$ & 167.34 & 208.87 & 0.80 \\
\hline
\end{tabular}

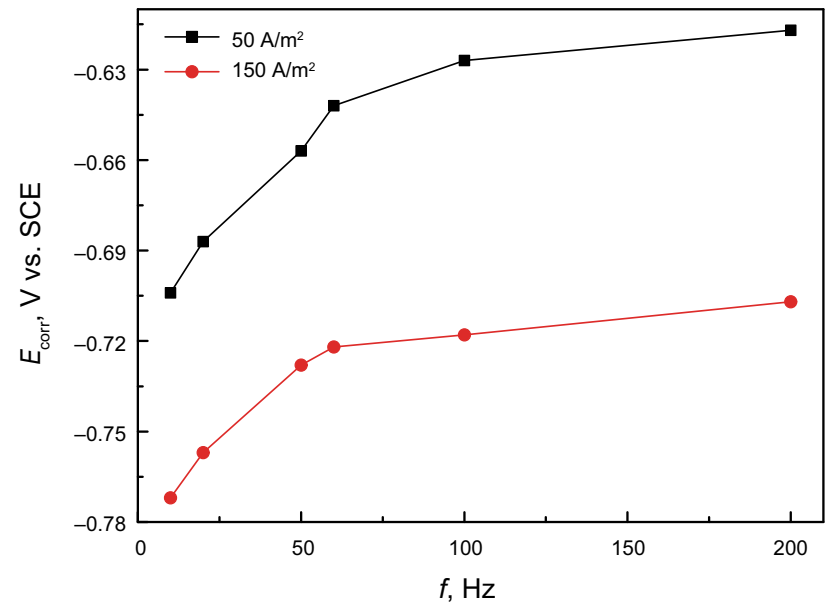

Fig. 8 Changes of the corrosion potential of X60 carbon steel electrode at various $\mathrm{AC}$ frequencies

participating in the electrode reaction decreased. The decrease in the Faradaic current would cause the peak voltage $\left(E_{\mathrm{p}}\right)$ to decrease from Eq. (2). From Tables 2 and 3, it can be seen that the Tafel slope ratios $\left(r=\beta_{\mathrm{a}} / \beta_{\mathrm{c}}\right)$ are lower than 1. Then, a combination of Eqs. (1) with (2) gives that, when $r<1$, the $E_{\text {corr,AC }}$ increased positively with a decrease in $E_{\mathrm{p}}$, which also can be found in Fig. 8 .

With an increase in the AC frequency, the Faradaic current decreases and then the anodic current density decreases. Thus, the asymmetry of changes of the anodic current density decreases during the positive half-cycle and negative half-cycle of AC interference. Based on the above analysis, the corrosion rate of the X60 carbon steel decreased with an increase in the AC frequency, as shown in Fig. 9.

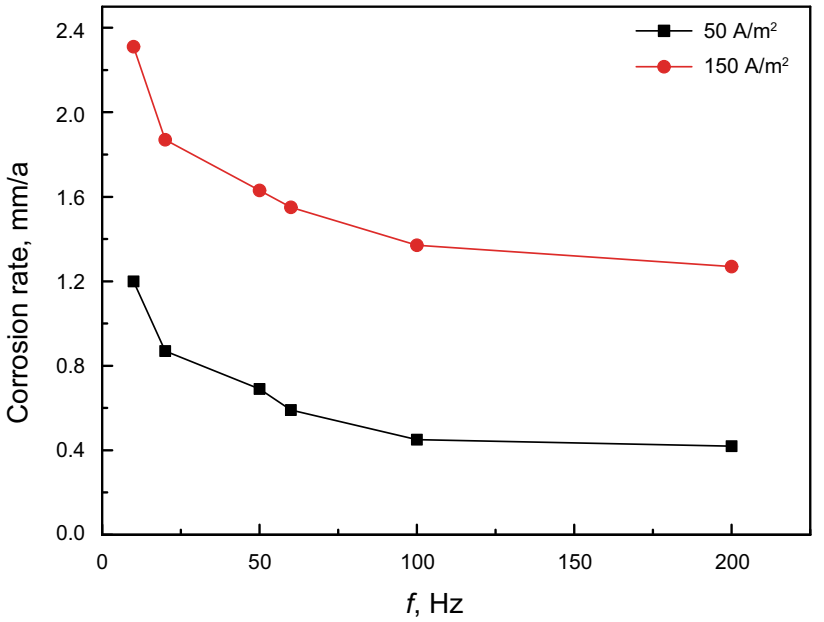

Fig. 9 Changes of the corrosion rate of the X60 carbon steel electrode at various $\mathrm{AC}$ frequencies

\subsection{Morphology of the corrosion surface}

In this research, a scanning electron microscope (SEM, FEI Quanta 200F) was used to observe the corrosion surfaces. After 2-h test, the corrosion product formed on the electrode surface was removed carefully by both mechanical and chemical methods. The mechanical methods, including light scraping and scrubbing, were used for removal of tightly adherent corrosion product. In the chemical procedure, a descaling solution containing $100 \mathrm{~mL} \mathrm{HCl}$ (special gravity 1.19 ), $0.7 \mathrm{~g}$ hexamethylenetetramine, and $100 \mathrm{~mL}$ distilled water was used. The SEM images of the X60 electrode surface are shown in Fig. 10. In the absence of $\mathrm{AC}$, the carbon steel surface was relatively smooth except 

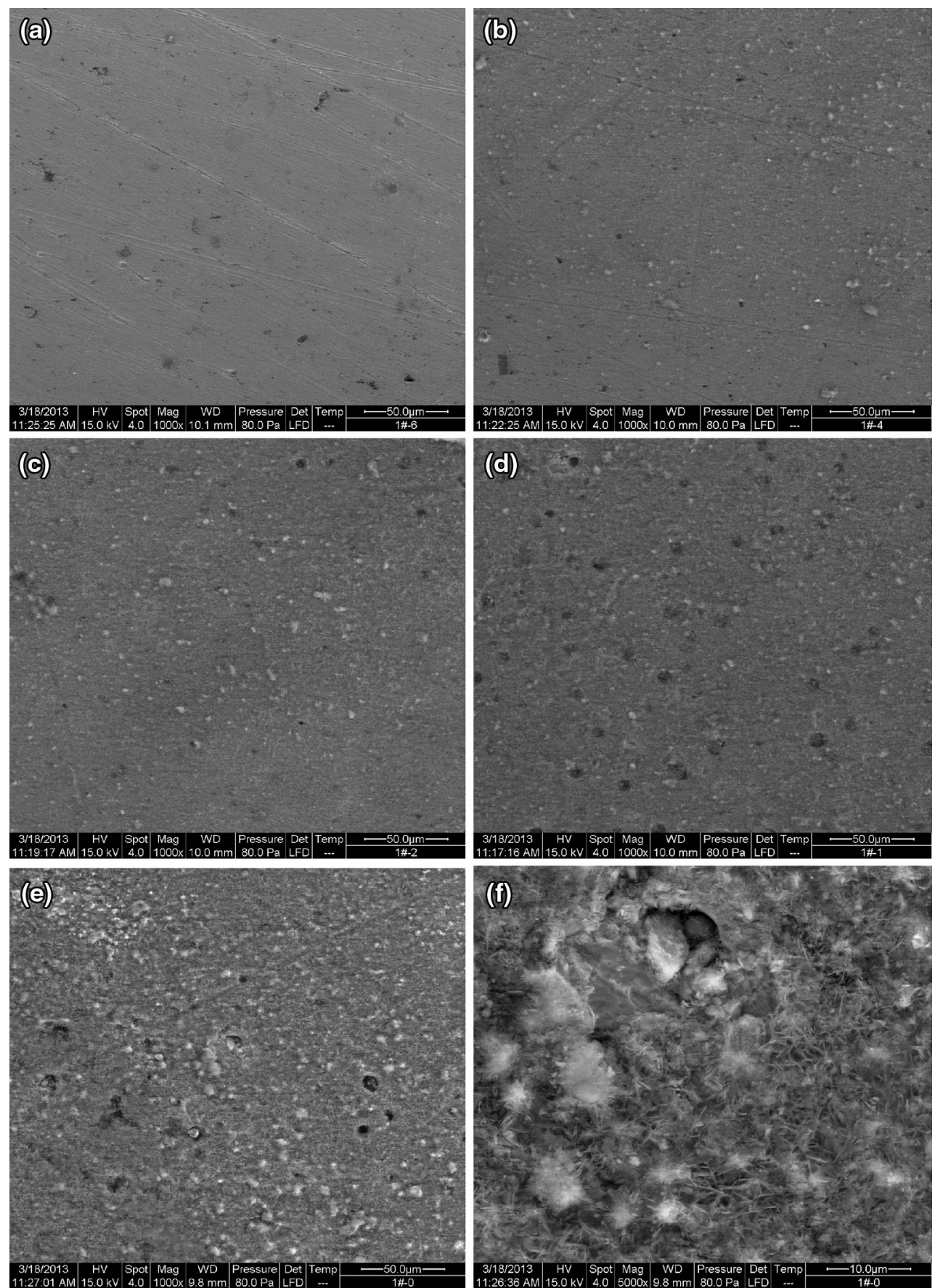

Fig. 10 SEM images of the X60 carbon steel electrode at various AC current densities and a frequency of $50 \mathrm{~Hz}$ after $2 \mathrm{~h}$ of test. a $0 \mathrm{~A} / \mathrm{m}^{2}$; b $20 \mathrm{~A} / \mathrm{m}^{2} ;$ c $70 \mathrm{~A} / \mathrm{m}^{2} ; \mathbf{d} 150 \mathrm{~A} / \mathrm{m}^{2}$; and e, f $200 \mathrm{~A} / \mathrm{m}^{2}$

for some slight corrosion marks, as seen in Fig. 10a. When a $20 \mathrm{~A} / \mathrm{m}^{2}$ AC current density was applied, uniform corrosion occurred on the carbon steel surface and the corrosion became serious, as shown in Fig. 10b. With further increase in the AC current density to 70 and $150 \mathrm{~A} / \mathrm{m}^{2}$, the corrosion was promoted and pitting corrosion appeared on the carbon steel surfaces, as seen in Fig. 10c, d. When the AC current density increased to $200 \mathrm{~A} / \mathrm{m}^{2}$, pitting corrosion became more severe and pitting holes got deeper than before, as shown in Fig. 10e, f. The corrosion form changed from uniform corrosion to pitting corrosion. This suggests that, at a low AC current density, a uniform corrosion occurs, while at a high AC current density, pitting corrosion occurs on the X60 electrode surface. That may be caused by the AC oscillation between the carbon steel surface and electrolyte solution, which leads to the pitting 
corrosion of carbon steel electrode (Nielsen et al. 2004; Nielsen and Galsgaard 2005).

\section{Conclusions}

Electrochemical tests on X60 carbon steel in simulated soil solution with AC interference led to the following conclusions:

(1) The presence of $\mathrm{AC}$ interference accelerated the corrosion of X60 carbon steel. With an increase in the AC current density, the corrosion potential shifted negatively and the net positive increase in the anodic current density increased during a complete AC cycle, which caused an increase in the corrosion rate of X60 carbon steel.

(2) With an increase in the AC frequency, the impedance of the electric double-layer capacitor decreased, which caused a decrease in the current through the polarization resistance. Thus, the decrease in the Faradaic current caused the anodic current density to decrease, which led to a decrease in the corrosion rate. The increase in the $\mathrm{AC}$ frequency also caused a positive shift of the corrosion potential of X60 carbon steel.

(3) Morphology investigations indicated that the corrosion of X60 carbon steel became more and more serious with an increase in the $\mathrm{AC}$ interference intensity. At a low AC current density, a uniform corrosion occurred, while at a high AC current density, pitting corrosion occurred on the X60 electrode surface. In general, the AC interference enhanced localized corrosion.

Acknowledgments This research is sponsored by the Projects in the National Science \& Technology Pillar Program during the Twelfth Five-year Plan Period (Grant No. 2011BAK06B01).

Open Access This article is distributed under the terms of the Creative Commons Attribution License which permits any use, distribution, and reproduction in any medium, provided the original author(s) and the source are credited.

\section{References}

Büchler M, Schöneich HG. Investigation of alternating current corrosion of cathodically protected pipelines: development of a detection method, mitigation measures, and a model for the mechanism. Corrosion. 2009;65(9):578-86.

Büchler M. Alternating current corrosion of cathodically protected pipelines: discussion of the involved processes and their consequences on the critical interference values. Mater Corros. 2012;63(12):1181-7.
Eliassen SL, Hesjevik SM. Corrosion management of buried pipelines under difficult operational and environmental conditions. In: Corrosion 2000, NACE, Paper No. 00724, Orlando. 2000.

$\mathrm{Fu}$ AQ, Cheng YF. Effects of alternating current on corrosion of a coated pipeline steel in a chloride-containing carbonate/bicarbonate solution. Corros Sci. 2010;52(2):612-9.

Fu AQ, Cheng YF. Effect of alternating current on corrosion and effectiveness of cathodic protection of pipelines. Can Metall Q. 2012;51(1):81-90.

Goidanich S, Lazzari L, Ormellese M, et al. Influence of AC on corrosion kinetics for carbon steel, zinc and copper. In: Corrosion 2005. NACE, Paper No. 05189, Houston. 2005.

Goidanich S, Lazzari L, Ormellese M. AC corrosion-Part 1: effects on overpotentials of anodic and cathodic processes. Corros Sci. 2010a;52(2):491-7.

Goidanich S, Lazzari L, Ormellese M. AC corrosion. Part 2: parameters influencing corrosion rate. Corros Sci. 2010b; 52(3):916-22.

Gummow RA. Cathodic protection considerations for pipelines with AC mitigation facilities. Pipeline Research Council International. Final Report of Contract PR-262-9809. 1999.

Ibrahim I, Takenouti H, Tribollet B, et al. Harmonic analysis study of the AC corrosion of buried pipelines under cathodic protection. In: Corrosion 2007. NACE, Paper No. 07042, Nashville. 2007.

Kajiyama F, Nakamura Y. Effect of induced alternating current voltage on cathodically protected pipelines paralleling electric power transmission lines. Corrosion. 1999;55(2):200-5.

Kim DK, Ha TH, Ha YC, et al. Alternating current induced corrosion. Corros Eng Sci Technol. 2004;39(2):117-23.

Lalvani SB, Lin XA. A theoretical approach for predicting ACinduced corrosion. Corros Sci. 1994;36(6):1039-46.

Lalvani SB, Zhang G. The corrosion of carbon steel in a chloride environment due to periodic voltage modulation: Part I. Corros Sci. 1995;37(10):1567-82.

Li ZL, Yang Y. Mechanism, influence factors and risk evaluation of metal alternating current corrosion. CIESC J. 2011;62(7):1790-9 (in Chinese).

Movley CM. Pipeline corrosion from induced A.C. In: Corrosion 2005. NACE, Paper No. 05132, Houston. 2005.

Muralidharan S, Kim DK, Ha TH, et al. Influence of alternating, direct and superimposed alternating and direct current on the corrosion of mild steel in marine environments. Desalination. 2007;216(1):103-15.

NACE Standard RP0169-96. Control of external corrosion on underground or submerged metallic piping systems. Houston: NACE; 1996.

Nielsen LV, Nielsen KV, Baumgarten B, et al. AC induced corrosion in pipelines: detection, characterization and mitigation. In: Corrosion 2004. NACE, Paper No. 04211, New Orleans. 2004.

Nielsen LV, Galsgaard F. Sensor technology for on-line monitoring of AC induced corrosion along pipelines. In: Corrosion 2005. NACE, Paper No. 05375, Houston. 2005.

Ormellese M, Goidanich S, Lazzari L. Effect of AC interference on cathodic protection monitoring. Corros Eng, Sci Technol. 2011;46(5):618-23.

Pagano MA, Lalvani SB. Corrosion of mild steel subjected to alternating voltages in seawater. Corros Sci. 1994;36(1):127-40.

Rehim SSA, Hazzazi OA, Amin MA, et al. On the corrosion inhibition of low carbon steel in concentrated sulphuric acid solutions. Part I: chemical and electrochemical (AC and DC) studies. Corros Sci. 2008;50(8):2258-71.

Song HS, Kho YT, Kim YG, et al. Competition of AC and DC current in AC corrosion under cathodic protection. In: Corrosion 2002. NACE, Paper No. 02117, Denver. 2002. 
Tang DZ, Du YX, Lu MX, et al. Effect of AC current on corrosion behavior of cathodically protected Q235 steel. Mater Corros. 2013. doi:10.1002/maco.201307234 (published online).

Wakelin RG, Sheldon C. Investigation and mitigation of AC corrosion on a $300 \mathrm{~mm}$ diameter natural gas pipeline. In: Corrosion 2004, NACE, Paper No. 04205, New Orleans. 2004.

Weng YJ, Wang N. Carbon steel corrosion induced by alternating current. J Chin Soc Corros Prot. 2011;31(4):270-4 (in Chinese).

$\mathrm{Xu}$ LY, Cheng YF. Effect of alternating current on cathodic protection on pipelines. Corros Sci. 2013;66:263-8.

Xu LY, Su X, Yin ZX, et al. Development of a real-time AC/DC data acquisition technique for studies of $\mathrm{AC}$ corrosion of pipelines. Corros Sci. 2012;61:215-23.
Yang Y, Li ZL, Wen C. Effects of alternating current on X70 steel morphology and electrochemical behavior. Acta Metall Sin. 2013;49(1):43-50 (in Chinese).

Yunovich M, Thompson NG. AC corrosion: mechanism and proposed model. In: 2004 international pipeline conference. Calgary: ASME; 2004. pp 183-95.

Zhu M, Du C, Li X, et al. Effect of AC current density on stress corrosion cracking behavior of $\mathrm{X} 80$ pipeline steel in high $\mathrm{pH}$ carbonate/bicarbonate solution. Electrochim Acta. 2014; 117:351-9. 